\title{
Value Addition to Millets
}

\author{
Dayakar Rao B* \\ ICAR-Indian Institute of Millets Research, India
}

Submission: July 30, 2018; Published: August 23, 2018

*Corresponding author: Dayakar Rao B, Principal Scientist \&CEO, ICAR-Indian Institute of Millets Research, Hyderabad, India,

Email: dayakar@millets.res.in

Keywords: Millets; Grains; Decortication; Fermentation; Flaking; Puffing; Grading; De-stoning; De-hulling; Glumes; Raw material; Sorghum products; Parboiled sorghum; Eatrite; IIMR, Diabetes; Cardiovascular disease; Blood pressure; Cancer; Farmer's income; Popping; Malting; Baking

\section{Opinion}

Indian Institute of Millets Research (IIMR) has pioneered in diversification of processing technologies in millet in order to provide wide options to consumers, otherwise prior to IIMR initiative due to absence of the convenient technologies in millets led to decline in their consumption. Developed millets value added Ready to Cook/Ready to Eat products, now value added technologies are made available for wider consumption to meet the consumer requirements (healthy and tasty).

\section{Description of Technology}

Millets are neither ready to eat nor ready to cook grains and need some kind of processing invariably for human consumption. Most commonly followed conventional processing methodologies are milling including decortication and size gradation, popping, malting, and fermentation. In the recent years the contemporary food processing technologies such as extrusion cooking, cold extrusion (vermicelli/ pasta/ noodles), baking, flaking and, puffing are applied for millets (Figure 1).

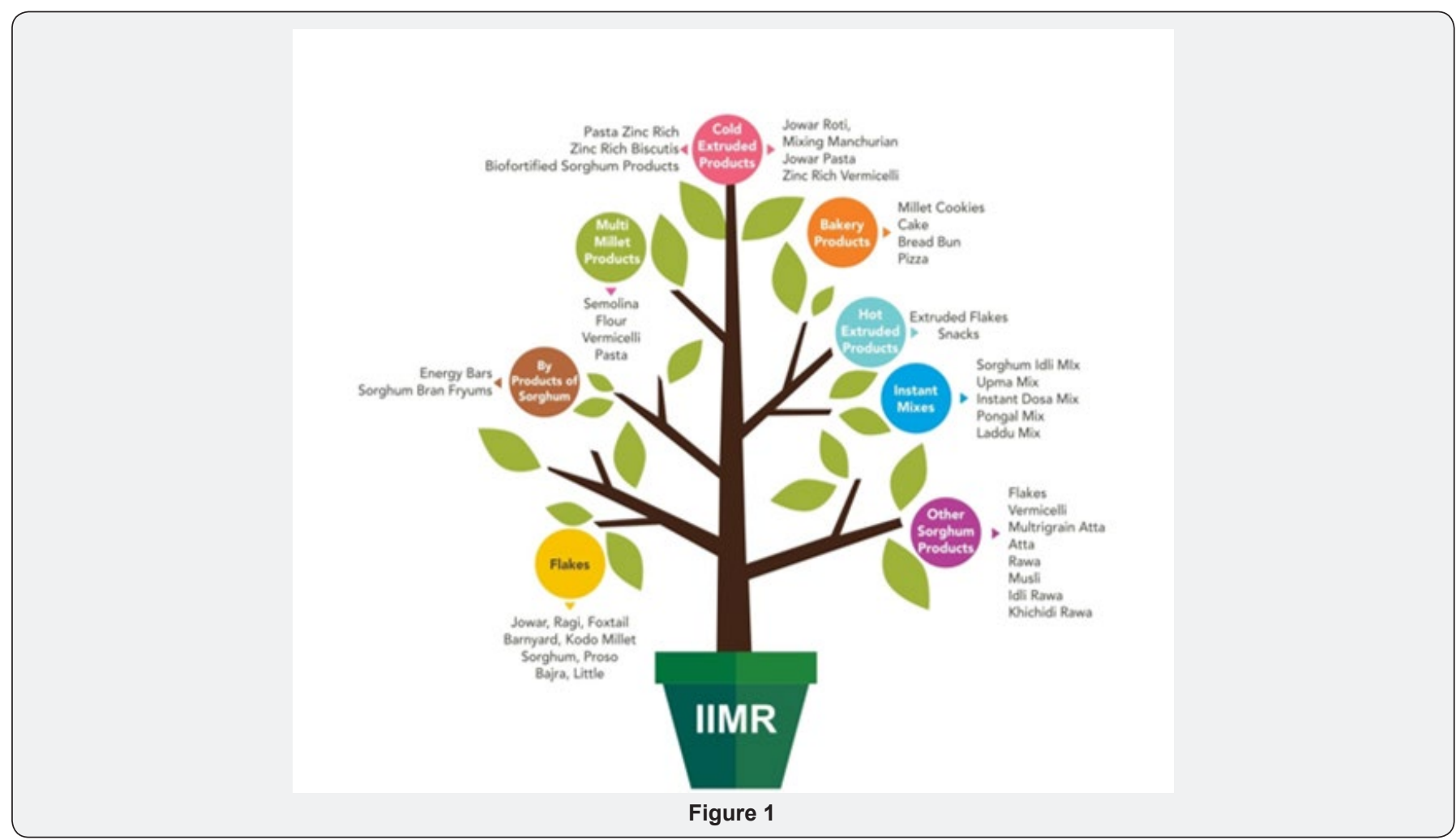




\section{Primary processing}

It is the processing to clean the grain through grading (depend on size of the grain), de-stoning (removal of stones) and de-hulling (polishing). The bulk operations of these processes can be done mechanically. Primary processing of the grain is removal of waste, stones and glumes from the grain that are necessary as it improves the storage of the grain.

\section{Secondary processing}

It involves use of the primary processed raw material in to different ready to cook sorghum products such as flour and semolina or suji (fine and medium), sorghum based multigrain flour, extruded products (vermicelli and pasta) and parboiled sorghum and ready to eat (biscuits, flakes, pops and multigrain roti) (Figure 2) .

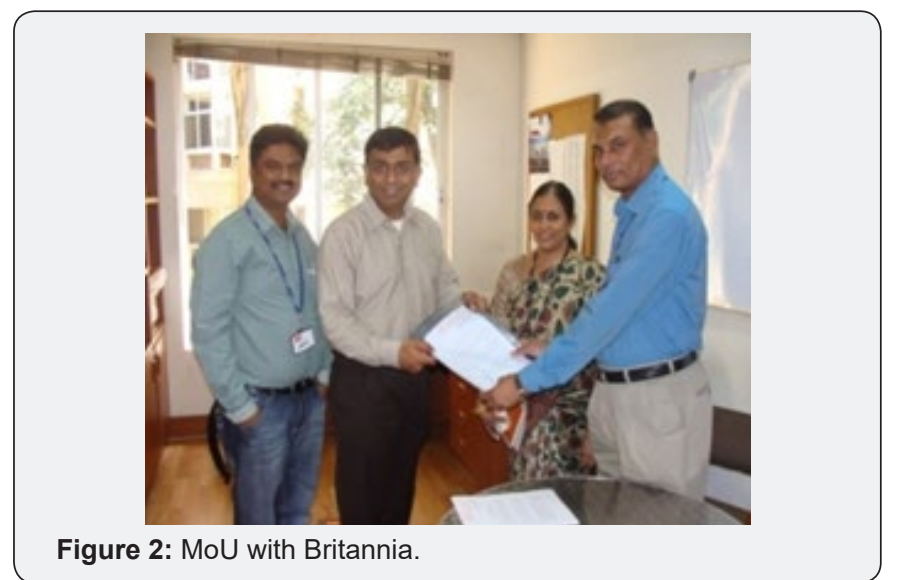

\section{Interventions}

a. Standardized primary processing of millets

b. Enhanced shelf life

c. Identified cultivars suitable for specific products

d. Nutrition profiling done e. Established nutritional superiority over existing rice/ wheat based products

f. Machines are developed and standardized to processing millets

g. Backward integrator model established in collaboration with ITC (ABD)

h. Farm gate processing helped in value addition to farmers

\section{Commercialization}

IIMR has developed 40 technologies of which 22 millet products are commercialized under the brand of "eatrite" solely to increase the consumption of millet in the country. Processing technologies were licensed by IIMR to 40 private companies some of them have established millet processing units in different states Telangana (8), Andhra Pradesh, Maharashtra (2), Tamilnadu (2), Karnataka (1), and New Delhi (3) to manufacture and promote sorghum and millet value added products to reach millet products to consumers. Multi National Company M/s Britannia Industries Ltd. signed MoU with IIMR to work jointly on R\&D of millet bakery products (biscuits) to include millets in nutri-choice (Figure $3 \& 4$ ).

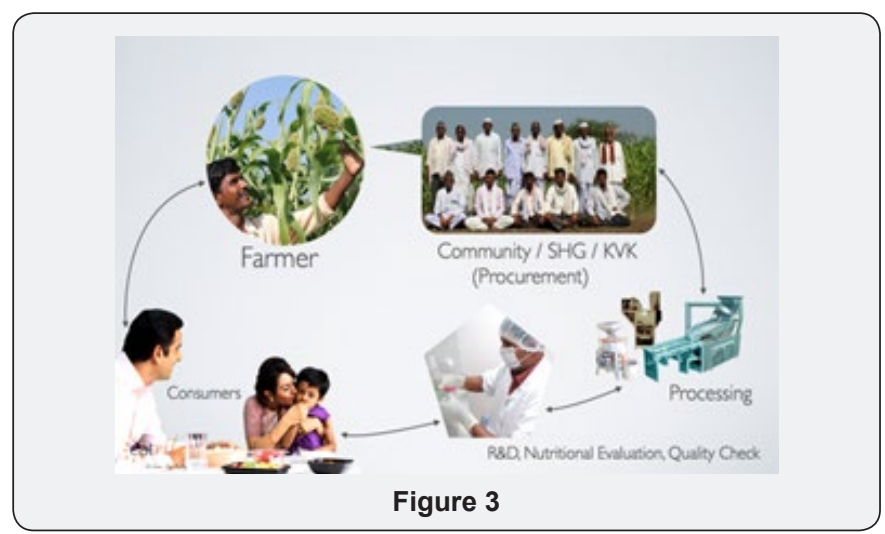

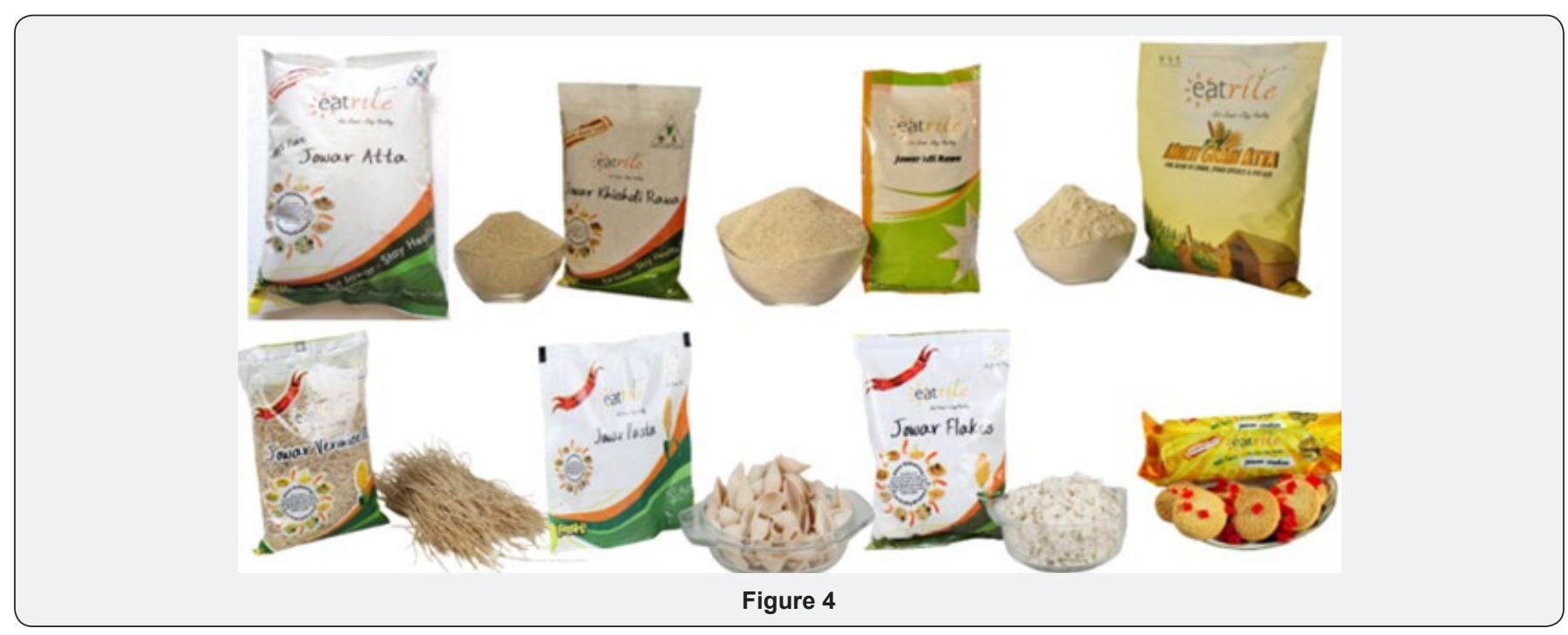




\section{Impact}

Value addition to the millets impact on different aspects primarily it creates demand and usage of millets in the consumer's daily diet in present lifestyle. Millets have good health benefits to prevent diabetes, cardiovascular disease, blood pressure, cancer etc. entrepreneurs come forward to start the millet processing units for this they required raw material so ultimately its impact on farmers to cultivate millets to meet the demand for processing and consumption of millets. On technological intervention has been successful in creating options for consumers in millets. This has led to impact both consumers whoever suffering from life style diseases as healthy choice but also to enhance the farmer's income.

This work is licensed under Creative Commons Attribution 4.0 License DOI: 10.19080/TTSR.2018.03.555603

\section{Your next submission with Juniper Publishers will reach you the below assets}

- Quality Editorial service

- Swift Peer Review

- Reprints availability

- E-prints Service

- Manuscript Podcast for convenient understanding

- Global attainment for your research

- Manuscript accessibility in different formats ( Pdf, E-pub, Full Text, Audio)

- Unceasing customer service

Track the below URL for one-step submission https://juniperpublishers.com/online-submission.php 